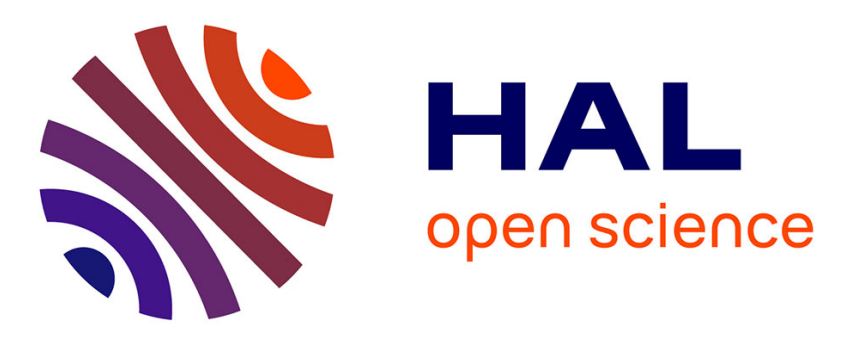

\title{
Hardened behavior of mortar based on recycled aggregate: Influence of saturation state at macro- and microscopic scales
}

Thang Le, Gwenn Le Saout, Eric Garcia-Diaz, Damien Betrancourt, Sébastien Rémond

\section{To cite this version:}

Thang Le, Gwenn Le Saout, Eric Garcia-Diaz, Damien Betrancourt, Sébastien Rémond. Hardened behavior of mortar based on recycled aggregate: Influence of saturation state at macro- and microscopic scales. Construction and Building Materials, 2017, 141, pp.479-490. 10.1016/j.conbuildmat.2017.02.035 . hal-02497763

\section{HAL Id: hal-02497763 \\ https://hal.mines-ales.fr/hal-02497763}

Submitted on 9 Mar 2020

HAL is a multi-disciplinary open access archive for the deposit and dissemination of scientific research documents, whether they are published or not. The documents may come from teaching and research institutions in France or abroad, or from public or private research centers.
L'archive ouverte pluridisciplinaire HAL, est destinée au dépôt et à la diffusion de documents scientifiques de niveau recherche, publiés ou non, émanant des établissements d'enseignement et de recherche français ou étrangers, des laboratoires publics ou privés. 


\title{
Hardened behavior of mortar based on recycled aggregate: Influence of saturation state at macro- and microscopic scales
}

\author{
Thang Le ${ }^{\mathrm{a}, \mathrm{b}, *}$, Gwenn Le Saout ${ }^{\mathrm{a}}$, Eric Garcia-Diaz ${ }^{\mathrm{a}}$, Damien Betrancourt ${ }^{\mathrm{b}}$, Sébastien Rémond ${ }^{\mathrm{b}}$ \\ ${ }^{a}$ C2MA, École des Mines d'Alès, 30100 Alès, France \\ ${ }^{\mathrm{b}}$ LGCgE-GCE, École des Mines de Douai, 59508 Douai, France
}

\section{H I G H L I G H T S}

- Effect limits the strength of RCA can be identified by using the De Larrard's approach. - Microstructure of RAC can be analyzed by image analysis and nano-indentation test.

- Initial moisture content of recycled sand little affect on mortar's hardened behavior.

Keywords:

Recycled concrete aggregate

Microstructure

Interfacial transition zone

Nano-indentation test

\begin{abstract}
A B S T R A C T
The influence of saturation state of recycled concrete aggregate (RCA) on the hardened behavior of mortar was investigated at macroscopic and microscopic scales.

At the macroscopic scale, a good adhesion between the RCA and the new cement matrix at 28 days of hydration is observed. However due to its intrinsic strength; a limiting effect of the RCA is found in comparison to natural aggregates (NA). This effect limits the strength of mortars for small values of effective water to cement ratio. In parallel, a low influence of moisture condition of used RCA on the mechanical properties is observed.

The microstructure of interfacial transition zone (ITZ) is characterized by image analysis of backscatter scanning electron microscopy (SEM) images at 2 and 28 days of hydration and nano-indentation test under SEM at 28 days of hydration. For mortars based on RCA, the average porosities in the ITZ of mortars with dried and over-saturated aggregates are identical. But the saturation state of aggregates has a significant influence on the distribution of porosity in the ITZ. The porosity in the ITZ of mortars containing RCA is larger than that of mortars made with NA. This difference can be explained by a higher effective water to cement ratio in the mortar based on RCA. This excess may be due to a lower value of absorption of RCA than that provided by the absorption estimated on RCA. The nano-indentation test under the SEM shows that the initial saturation state of recycled sand (dry or over-saturated) does not influence the micro-hardness of the new cement matrix.
\end{abstract}

\section{Introduction}

The construction industry is a large consumer of natural resources. In the same time, it generates large amounts of construction and demolition wastes that eventually end up in landfills without any form of recovery. According to the European Union directive 2008/98/EC, one aim is to increase recycling of construction and demolition waste to at least $70 \%$ by the year 2020 [1]. The recycled concrete aggregates (RCA) have the potential to replace

* Corresponding author at: LGCgE-GCE, École des Mines de Douai, 59508 Douai, France.

E-mail address: thang.le.esct@gmail.com (T. Le). natural resources however it is necessary to assess the effect of recycled aggregates on the final concrete.

RCA are composed of a mixture of natural aggregates roughly coated with hardened cement paste. The presence of cement paste which is very porous leads to a greater absorption of water that must be taken into account in the formulation of concrete. In concrete, the amount of water available for cement hydration, the quality of the bond zone between aggregates and cement paste and the quality of the RCA strongly influence the mechanical properties.

The quality of this bond zone depends on the presence or not, between the aggregate and the bulk cement paste, of a more porous cement paste zone than the bulk paste called interfacial tran- 
sition zone (ITZ). Several authors [2-5] have studied in details, experimentally and numerically, the microstructure of the ITZ, its formation mechanisms and its properties.

The ITZ is constituted by a cement paste with a microstructure gradient between the bulk cement paste and the aggregate: the porosity and the Portlandite content increases in the ITZ from the bulk cement paste to the aggregate surface. This microstructure gradient is mainly the consequence of the "wall effect" exerted by the aggregate on the fine cement particles. Because of this "wall effect" the initial cement content decreases and respectively the water content increases from the bulk cement paste to the aggregate surface. The thickness of the disturbed area by the "wall effect" is of several tens of microns and corresponds to the initial thickness of the ITZ. During the hardening and because of a filling of the porosity by the hydrated products the depth of the ITZ generally decreases. A mechanism of transport of the hydration products (mainly Portlandite) which occurs from the rich to the poor cement area is also observed. Because of the Portlandite transport, the formation of a "duplex film" of a few microns rich in Portlandite can be observed at the aggregate surface. In the case of recycled aggregate concrete, three different kinds of ITZ are present (Fig. 1): ITZ within the RCA (old ITZ), ITZ between the old and new cement paste (new ITZ), ITZ between the new paste and natural aggregate (NA) present in the RCA.

The strength of recycled aggregate concrete may depend on the strength of the old ITZ within the RCA, the new ITZ between the old and new cement paste or between the new cement paste and NA, the mechanical properties of the new cement paste, or the intrinsic mechanical properties of RCA. In the literature, some studies shown that the weak link in the recycled aggregate concrete is the new ITZ between the new cement paste and RCA [6]. However, the weak link depends also on the relative strength between old and new ITZ $[7,8]$. RCA contains part of adherent cement paste that could reduce their mechanical properties. Microcracks due to the crushing process are also one of the reasons of the lower strength of RCA in comparison to natural aggregates [7,9-11]. This weak link could be responsible for the limitation of strength of recycled aggregate concrete, called "ceiling effect", which characterizes the intrinsic properties of aggregates [12].

The difficulty to control the quality of recycled aggregate leads to different conclusions in the literature. Contradictory opinions on the influence of absorption on the quality of ITZ and on mechanical properties can be found $[9,13,14]$. The influence of the saturation state of natural aggregates with different absorption coefficients on the properties of mortars prepared with the same effective water content has been studied by Nguyen [13]. In the case of low porosity aggregate, a little or no difference in the porosity of

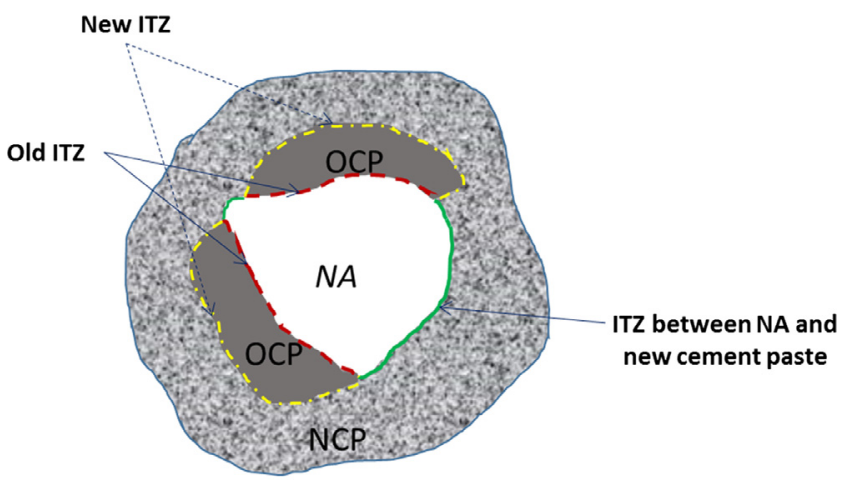

NA: Natural Aggregate OCP: Old cement paste NCP: New cement paste

Fig. 1. Illustration of different ITZs in RAC. the ITZ between mortars based on dry and wet sand all along the distance from aggregate is observed. However, in the case of more porous aggregates, the porosity in the ITZ is much higher for the mortars based on wet sand than for mortars based on dry sand. In the case of large absorption coefficient, the higher porosity in the ITZ obtained for saturated aggregates in comparison to dry ones could explain the lower mechanical strengths in the former case. Zhao et al.[14] obtained similar results with mortars containing RCA. On the contrary, Tam et al. [9] showed that the quality of the new ITZ, between the new and old cement paste, is improved by using wet aggregates.

As a conclusion, the quality of ITZ depends on the surface characteristics of aggregate particles, chemical bonding, absorption and saturation state of aggregate. A few qualitative studies have been carried out on the new ITZ in the recycled aggregate concrete and on the influence of saturation state of aggregate on its properties. However, there is no quantitative study of new ITZ in RAC and very few studies carried out on the "ceiling effect" of RCA [15].

The aim of this work is to characterize the influence of moisture condition of recycled aggregates on the hardened behavior of mortars at macro and microscopic scales. Firstly, the possible influence of RCA on the limitation of strength of recycled aggregate concrete ("ceiling effect") is studied. The influence of moisture conditions of recycled aggregate on the macroscopic properties is also investigated. Secondly, the microstructure of recycled mortars is characterized by image analysis of the ITZ and by nano-indentation test under the SEM. The ITZ between the old and the new cement paste for different ages of curing and different initial saturation states of recycled sand is characterized at a micro scale by image analysis. Then it is compared to ITZ of mortar based on natural aggregates. The micro-hardness of different phases in the mortar based on recycled aggregates (natural aggregate, old and new cement pastes) is then characterized by nano-indentation test under the SEM. Finally, the link between the saturation state, the macro and microscopic properties is discussed.

\section{Materials and methods}

\subsection{Properties of raw materials}

The RCA (RS 1) and natural sand (NS) are provided by the French National Project RECYBETON [16]. The RCA was crushed on the site of DLB Gonesse (France) from the destruction of real concrete structure. No washing was used in the production process. For the preparation of mortars, the RCA (RS_1) was sieved and recomposed from six size fractions to obtain the same particle size distribution as the natural sand (NS) (Fig. 2). The recomposed recycled sand is labeled RS_2. The physical properties of the sands are given in Table 2. The cement used in the study is an ordinary Portland cement OPC (CEM II/A-L 42,5N). The mineralogical composition is shown in the Table 1 . The class of cement at 28 days (noted $R c_{28}^{c i}$ ), measured according to European Standard EN 196-1 [17], is 51.3 MPa.

Measurement of the moisture content and absorption coefficient of aggregates is essential, because if the methods of formulation enable determination of the optimum dosage of water in concrete, it should take into account the water contained or absorbed by the aggregates to determine the effective water content. The effective water content is defined in the case of absorbing aggregates as the difference between the total water present in the fresh concrete and the water absorbed by aggregates.

In order to study the effect of saturation degree of aggregates on the microstructure and mechanical properties, wet and dry sand (respectively labeled WS and DS) have been used. DS was obtained by oven drying at $105^{\circ} \mathrm{C}$ until constant mass. WS was pre-saturated in a sealed plastic box and stored in a room at $20^{\circ} \mathrm{C}$ for one week. The amount of water added to the pre-saturation is equal the amount of absorbed water $\left(W_{24 h}\right)$ plus $10 \%$, so the water content is equal to $W_{24 h}+10 \%$. We can note that we obtain a supersaturated state in comparison to the saturated surface dry state (SSD state). The water absorption of NS was determined by standard method EN 1097-6. However, in the case of RS_1 and RS_2, the water absorption was measured by extrapolation $[18,19]$. The measure and comparison of the water absorption coefficient of the present recycled sand by different methods have been already discussed in a previous paper [18]. So the water absorption of RS_1 and RS_2 are 9.0 and $10 \%$ respectively. Table 2 presents the physical properties of the used sands in this study. 


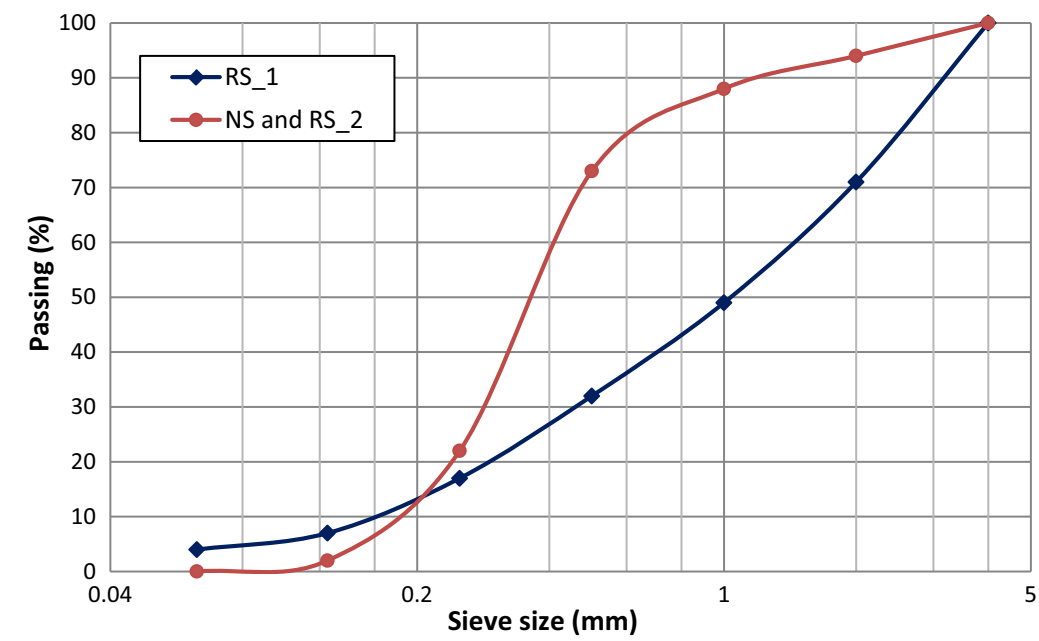

$R S_{-}$1: recycled sand as delivered

$R S_{-}$2: recycled sand after recomposition to obtain the same granulometry as natural sand

Fig. 2. Cumulated particle size distributions of the sands.

Table 1

Mineralogical composition of cement determined by XRD-Rietveld analysis.

\begin{tabular}{|c|c|c|c|c|c|c|c|}
\hline & & $\mathrm{C}_{3} \mathrm{~S}$ & $\mathrm{C}_{2} \mathrm{~S}$ & $\mathrm{C}_{3} \mathrm{~A}$ & $\mathrm{C}_{4} \mathrm{AF}$ & Calcite & Gypsum \\
\hline CEM II/A-L $42.5 \mathrm{~N}$ & $(\%)$ & 53.5 & 12.8 & 4.3 & 13.0 & 10.7 & 3.6 \\
\hline
\end{tabular}

Table 2

Physical properties of the sands.

\begin{tabular}{|c|c|c|c|c|}
\hline Sands & & NS & RS_1 & RS_2 \\
\hline Absolute particle density ${ }^{\mathrm{a}}$ & $\left(\mathrm{g} \mathrm{cm}^{-3}\right)$ & 2.67 & 2.65 & 2.64 \\
\hline Oven-dried particle density ${ }^{\mathrm{a}}$ & $\left(\mathrm{g} \mathrm{cm}^{-3}\right)$ & 2.63 & 2.23 & 2.25 \\
\hline Saturated and surface dried particle density ${ }^{\mathrm{a}}$ & $\left(\mathrm{g} \mathrm{cm}^{-3}\right)$ & 2.64 & 2.39 & 2.41 \\
\hline Water absorption at $24 \mathrm{~h}, \mathrm{WA}_{24 \mathrm{~h}}$ & $(\%)$ & $0.5^{\mathrm{a}}$ & $9.0^{\mathrm{c}}$ & $10.0^{c}$ \\
\hline water content in wet sand ${ }^{\mathrm{b}}, \mathrm{W}_{\mathrm{Ws}}$ & $(\%)$ & 10.5 & 19.0 & 20.0 \\
\hline
\end{tabular}

a Measured according to the European standard EN 1097: 2001-06.

b Calculated as Eq. (1).

c Measured using extrapolation method [18,19].

The relative amount of water $\mathrm{W}_{\mathrm{WS}}$ in wet sand is calculated as:

$W_{\text {Ws }}=100 * \frac{M_{2}-M_{1}}{M_{1}}$

where $M_{1}$ and $M_{2}$ are respectively the weight of dry and wet sand.

\subsection{Macroscopic study: "ceiling effect"}

At the macroscopic scale, we first investigate if the aggregate could exert a "ceiling effect" on the mechanical properties due to its intrinsic strength; a limiting effect of the aggregate [12]. According to De Larrard et al. [12], the compressive strength of concrete or mortar can be related to the compressive strength of the cement matrix by the Eq. (2):

$R_{C}=\frac{p * R_{c m}}{q * R_{c m}+1}$

where $R_{c}$ and $R_{c m}$ are respectively the compressive strengths of mortar and of cement matrix in MPa. " $\mathrm{p}$ " (without dimension) and " $\mathrm{q}$ " (in $\mathrm{MPa}^{-1}$ ) are empirical constants depending on the type of aggregate. "p" presents the quality adhesion between the aggregate and the cement matrix. The " $\mathrm{p} / \mathrm{q}$ " ratio could characterize the "ceiling effect" on the compressive strength of mortar that can be attributed to the lower strength of aggregate.

The compressive strength of the cement matrix is calculated by the Eq. (3) [12]:

$R_{c m}=13.4 * R_{c 28}^{c i} *\left(\frac{V_{c}}{V_{c}+V_{w}+V_{a}}\right)^{2.85} * M P T^{-0.13}$ where $R_{c 28}^{c i}$ is the class of cement at 28 days; Vc, Vw, Va are respectively the volume of cement, water and air in the mortar; MPT is the maximum paste thickness between two close aggregates calculated from Eq. (4) [12]:

$M P T=D_{\max } *\left(\sqrt[3]{\frac{g^{*}}{g}}-1\right)$

where $D_{\max }$ is the maximal size of aggregates; $g$ is the aggregate volume in a unit volume of mortar or concrete; $\mathrm{g}^{*}$ is the granular packing density that could be determined by Eq. (5) for crushed aggregate [12]:

$g^{*}=1-0.45 *\left(\frac{d_{\min }}{D_{\max }}\right)^{0.19}$

Here, $d_{\min }$ and $D_{\max }$ are the minimum and maximum sizes of aggregates, corresponding to 10 and 90 percent passing, respectively.

In this study, different $\mathrm{W}_{\text {eff }} / \mathrm{C}$ ratios were used in order to vary the compressive strength of the cement matrix for mortars based on RCA. According to Eq. (2), for high cement matrix strengths $\left(R_{c m} \gg 1 / q\right.$, low $\left.W_{\text {eff }} / C\right)$, the mortar strength is given by:

$R_{C} \approx \frac{p}{q}$

This ratio is expected to be controlled by the intrinsic strength of the aggregate ("ceiling effect").

For low cement matrix strengths $\left(\mathrm{R}_{\mathrm{cm}} \ll 1 / \mathrm{q}\right.$, high $\left.\mathrm{W}_{\mathrm{eff}} / \mathrm{C}\right)$, we have:

$R_{C} \approx p * R_{c m}$ 
In this case, the strength of mortar is controlled by the strength of cement matrix.

In order to identify p and q parameters, mortars (called RM1-Sat) were prepared with pre-saturated recycled sand (RS_1). Moreover, a super plasticizer was added in order to obtain self-compacting mortars with a slump flow comprised between 300 and $350 \mathrm{~mm}$. With this preparation procedure, the volume of entrapped air of all the studied mortars was 0\% (measured according to EN 413-2 [20]). The mortar compositions are shown in Table 3.

In order to study the influence of saturation state of aggregates, three additional mortars (called RM1-Dry) were also manufactured with dry sand $\left(\mathrm{W}_{\mathrm{eff}} / \mathrm{C}=0.38\right.$, 0.53 and 0.68 ).

\subsection{Microscopic study: ITZ}

The second part of the work was dedicated to the influence of the moisture conditions of RCA on the microstructure of mortars. Four mortars were manufactured with a same $\mathrm{W}_{\text {eff }} / \mathrm{C}$ of 0.5 and an identical volume of sand of around 60\%. Mix proportions are presented in Table 4. The recycled sand used in this case is RS_2 with the same particle size distribution as natural sand.

$40 \times 40 \times 160 \mathrm{~mm}^{3}$ mortar samples were cast and stored 1 day at $20^{\circ} \mathrm{C}$ and $95 \%$ relative humidity. The specimens were demoulded the following day, then cured under water at $20^{\circ} \mathrm{C}$ and tested at 2 and 28 days. Compressive strengths were measured according to the European standard EN 196-1 [17].
2.3.1. Image analysis of backscatter SEM images

For the microstructural investigations, pieces of hydrated samples of $1 \times 2 \times 2 \mathrm{~cm}^{3}$ were cut from the core of $40 \times 40 \times 160 \mathrm{~mm}^{3}$ mortar samples [13] Two main methods are available to stop hydration and remove the water: freeze drying and solvent exchange. The disadvantage of the freeze drying method is the presence of many micro cracks in the cement matrix [21]. We chose the solvent exchange method using isopropanol-2 as solvent and immersion of the sample for one week. The samples were then passed to vacuum to remove solvent and stored in a desiccator with silica gels. Afterwards, they were impregnated using a low viscosity epoxy resin in vacuum condition and polished down to $0.25 \mu \mathrm{m}$ using diamond pastes [13]. The samples were further coated with carbon $(\sim 5 \mathrm{~nm})$ and examined using a Quanta 200 FEG scanning electron microscope (SEM) from FE coupled to an Oxford INCA X-sight energy dispersive X-ray spectroscopy (EDX) analyzer. The sample was introduced into the chamber of the SEM setting a mode high vacuum to avoid disruptions and analytical distance of $10 \mathrm{~mm}$. We chose a voltage of $15 \mathrm{kV}$ for optimum observation through the analysis of secondary and backscattered electrons. A slow scanning speed was chosen (1-2 photos/min) to capture an image. SEM is used in imaging mode "backscattered electron diffraction" (Backscattered electrons (BSE)) for studies of polished sections. This observation mode provides better contrast between different phases in the cementitious material.

Backscattered electron imaging (BSE) has been used to study the interfacial transition zone (ITZ) in mortars following the lead of Scrivener et al. [22]. Around 30 BSE images of a field $182 \times 167 \mu \mathrm{m}^{2}$ that corresponds to a resolution of $0.18 \mu \mathrm{m}$ per pixel, were acquired which makes it possible to detect elements with dimensions $0.03 \mu \mathrm{m}^{2}$. The fractions of anhydrous phase, hydrates and porosity were

Table 3

Mixing compositions of mortars to evaluate the "ceiling effect".

\begin{tabular}{|c|c|c|c|c|c|c|c|c|}
\hline $\mathrm{W}_{\mathrm{eff}} / \mathrm{C}$ & & 0.38 & 0.43 & 0.48 & 0.53 & 0.58 & 0.63 & 0.68 \\
\hline Dry sand (RS_1) & (g) & 1155 & 1155 & 1155 & 1155 & 1155 & 1155 & 1155 \\
\hline Cement & (g) & 450 & 450 & 450 & 450 & 450 & 450 & 450 \\
\hline Effective water & (g) & 171 & 193.5 & 216 & 238.5 & 261 & 283.5 & 306 \\
\hline Absorption water & (g) & 102 & 102 & 102 & 102 & 102 & 102 & 102 \\
\hline Total water & (g) & 273.0 & 295.5 & 318.0 & 340.5 & 363.0 & 385.5 & 408.0 \\
\hline Pre-saturated water & (g) & 231 & 231 & 231 & 231 & 231 & 231 & 231 \\
\hline Super-plasticizer & $(\mathrm{ml})$ & 18.0 & 13.0 & 8.0 & 5.0 & 4.5 & 2.5 & 2.0 \\
\hline
\end{tabular}

Table 4

Mix proportions of the mortars with different moisture states of sand for the investigation of microstructure.

\begin{tabular}{|c|c|c|c|c|c|}
\hline \multirow[b]{2}{*}{ Moisture state of sand } & & \multicolumn{2}{|c|}{ Mortar of natural sand } & \multicolumn{2}{|c|}{ Mortar of recycled sand } \\
\hline & & Dry & Over-saturated & Dry & Over-saturated \\
\hline Name & & NM-Dry & NM-Sat & RM2-Dry & RM2-Sat \\
\hline $\mathrm{W}_{\mathrm{eff}} / \mathrm{C}$ & & 0.5 & 0.5 & 0.5 & 0.5 \\
\hline Dry sand (RS_2) & (g) & 1350 & 1350 & 1155 & 1155 \\
\hline Water absorption coefficient & $(\%)$ & 0.5 & 0.5 & 10.0 & 10.0 \\
\hline Cement & (g) & 450 & 450 & 450 & 450 \\
\hline Effective water ( $\left.\mathrm{M}_{\mathrm{eff}}\right)$ & (g) & 225 & 225 & 225 & 225 \\
\hline Absorbed water & (g) & 6.8 & 6.8 & 115.5 & 115.5 \\
\hline Total water & (g) & 231.8 & 231.8 & 340.5 & 340.5 \\
\hline Pre-saturated water & (g) & 0 & 141,8 & 0 & 231 \\
\hline Batch water & (g) & 231.8 & 90.0 & 340.5 & 109.5 \\
\hline
\end{tabular}
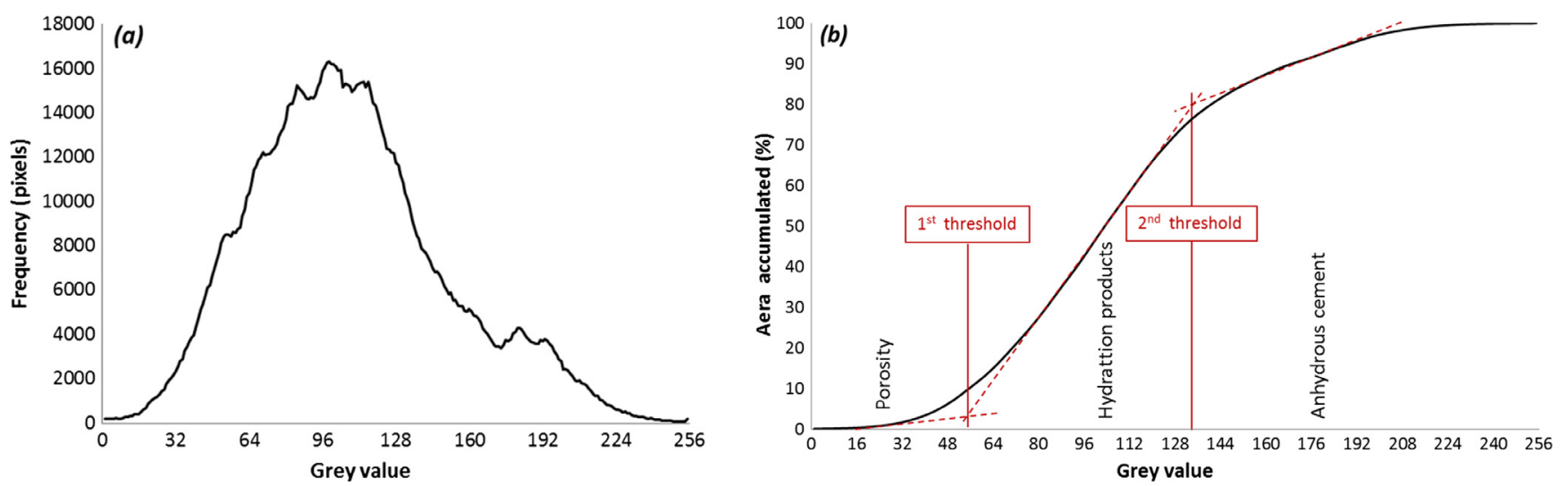

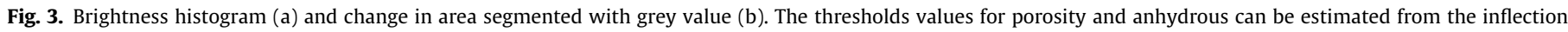
points. 
evaluated in 8 bands of $10 \mu \mathrm{m}$ in width [23-25]. The results were plotted against distance from the aggregate and averaged over the 30 images. The relative area of each component in each band was calculated from the grey level histogram. The lower threshold level of pores has been set to zero (black pixel). Several methods are available for determining the thresholds on the histogram of an image $[5,26,27]$. In this study, we used inflection points on the graph of air accumulated depending on the intensity of the image to determine the thresholds as proposed by Wong et al. [28]. An example of the determination of the thresholds using this method is presented in Fig. 3.

A visual comparison of the compatibility between the base image and the images of phases is first carried out to validate the selected thresholds. To facilitate comparison, the images are enlarged. If there is an underestimation or overestimation of the phases, the thresholds are shifted until the isolated phases are compatible with the base image (Fig. 4).
The Delesse principle states that the two-dimensional areas of profiles of components are related to the three-dimensional volumes occupied in space by these components, assuming random distribution and random orientation of components [29]. The porosity deduced by this method is limited by the pixel size, thus very fine capillary and C-S-H pores cannot be separated and are included in the area of hydrated products [23]. The distance measured from the aggregate surface on a random section overestimates the true perpendicular distance in three dimensions $[5,30]$. It is difficult to correct the distances unless measurements are made only on interfaces that are normal to the image planes as in [31]. In this study, the distance from aggregate is the distance measured on 2D sections without corrections. Considerations with regards to image analysis and its limitations in the study of the ITZ have been discussed in literature and are not detailed here $[5,28]$. When the thresholds are known, segmentation phase is performed using a programmed Matlab tool.
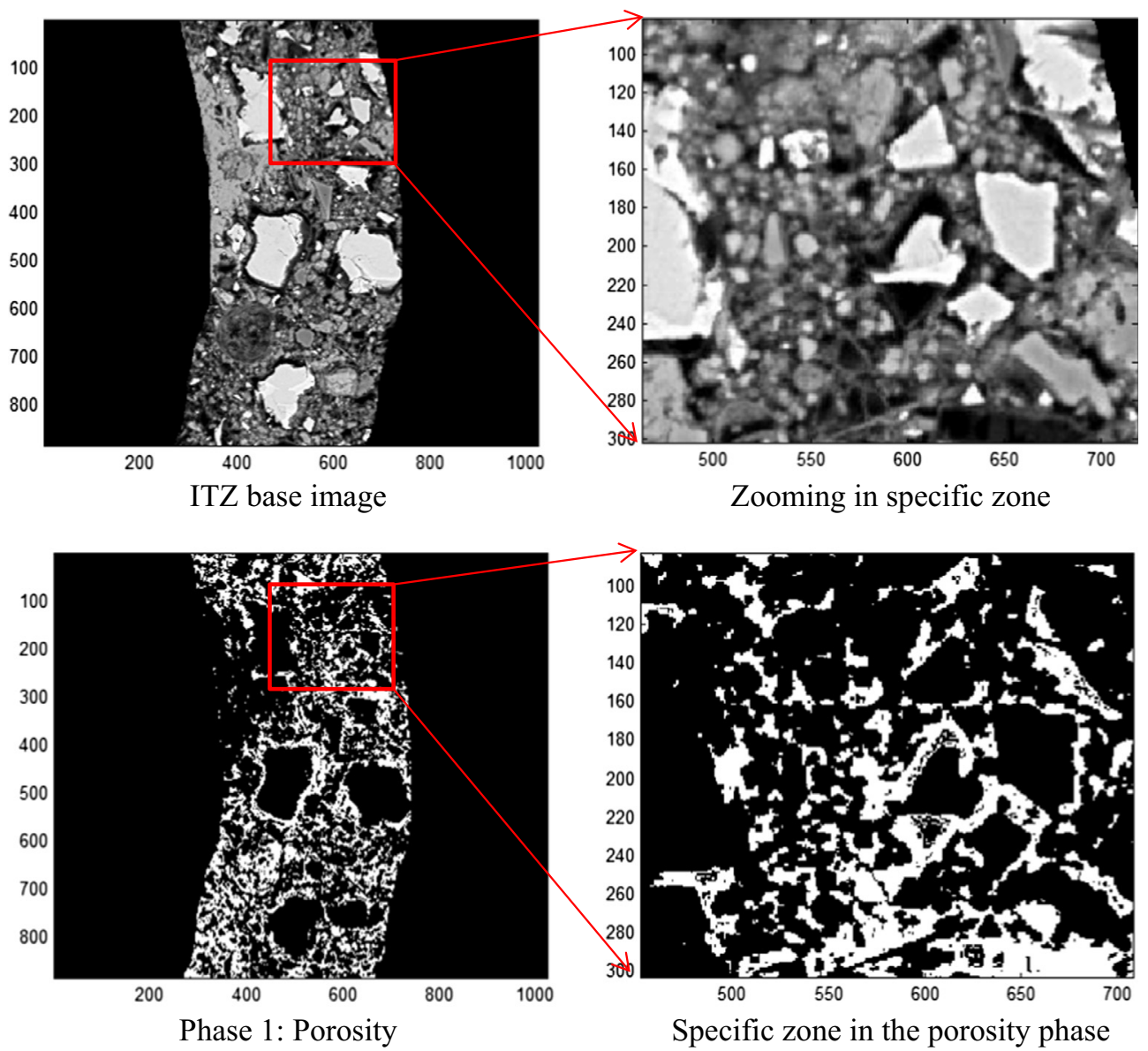

Specific zone in the porosity phase
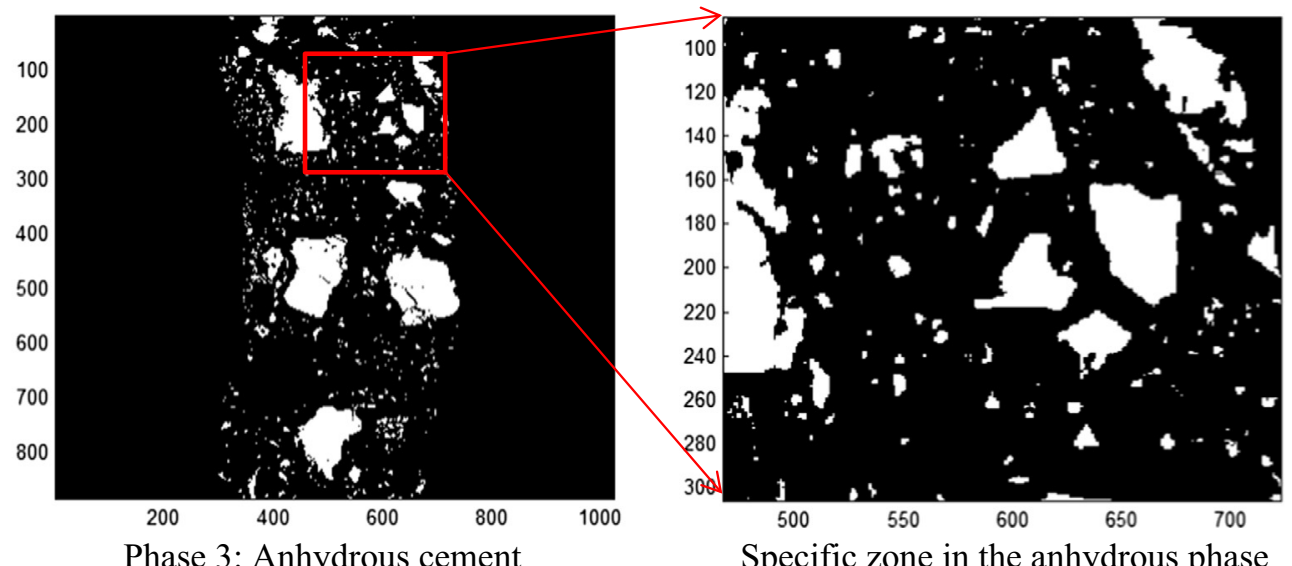

Phase 3: Anhydrous cement

Specific zone in the anhydrous phase

Fig. 4. Comparison of specific zones between base images and binary images of porosity and anhydrous phases. 


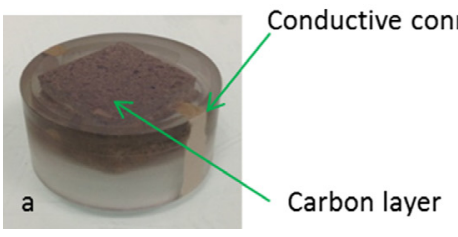

a) Microstructure observation sample

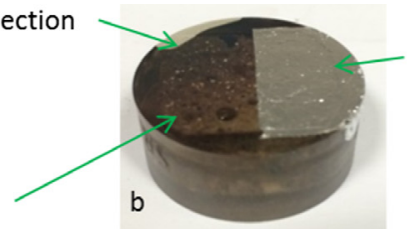

b) Nano-indentation test sample

Fig. 5. Samples for microstructure observation and nano-indentation test.

\subsubsection{Nano-indentation test under SEM}

For the nano-indentation investigations, the sample preparation is similar to the SEM sample preparation. The difference is the size of the sample $\left(1 \times 1.5 \times 1.5 \mathrm{~cm}^{3}\right)$ and the surface of sample partly covered with an aluminium foil used as a reference for the laser (Fig. 5). The instrument is a SEM type of HITACHI S$4300 \mathrm{SE} / \mathrm{N}$ with an included instrument of indentation developed at civil engineering and environmental department (Ecole des Mines de Douai). The advantages of this system are: to allow working with a smaller scale under the SEM than under an optical microscope; to permit choosing a preferred indentation zone to avoid errors (porosity, damaged zone, crack, etc.); to allow working in situ with an included camera to observe the behavior of material during the test.

The used indenter is a modified Berkovich type with a maximal diagonal of $20 \mu \mathrm{m}$ allowing to obtain an identical equivalent cone than a Vickers indenter. The geometry parameters of this indenter are presented in Fig. 6 and Table 5 .

A 3D moving table included in the instrument of indentation is used to select the indented area and to measure the indentation depth with an accuracy of $10 \mathrm{~nm}$. The vertical displacement of indenter is measured by the laser.

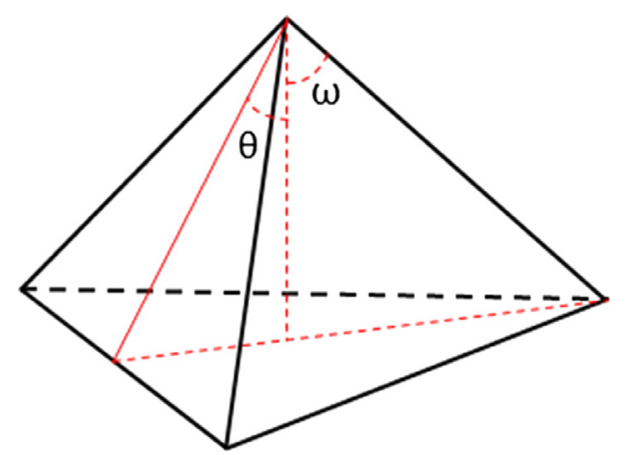

Fig. 6. Geometric illustration of modified Berkovich indenter.
Included in the instrument of indentation is a cell of force with $1 \mathrm{~N}$ maximum load with an accuracy of $0.5 \mathrm{mN}$. The maximum and minimum loading speeds are $100.0 \mathrm{mN} / \mathrm{s}$ and $0.10 \mathrm{mN} / \mathrm{s}$ respectively. In this study, the maximum force $100 \mathrm{mN}$ is chosen to obtain a reasonable size of marked with a speed load of $3 \mathrm{mN} / \mathrm{s}$.

An observation under the SEM is first performed to select an appropriate area. Firstly, the sample is observed in EDS mode (elementary analysis) to identify the concentration differences between old and new cement pastes. In particular, mapping of iron allows identifying the new cement paste as new cement contains $13 \%$ of $\mathrm{C}_{4} \mathrm{AF}$. An accurate identification of the boundary between old and new paste is however delicate. This is why the hardness of the different phases is measured far away from the boundaries. Once the phase has been identified, the indenter is then moved to this point to perform the test. The strength and vertical displacement of the indenter (depth of penetration) are recorded instantaneously to plot the load-displacement curve. This test is performed at least on 12 points for each phase (Fig. 7).

In this study, the Martens micro-hardness $\left(\mathrm{H}_{\mathrm{M}}\right)$ value based on the maximum depth obtained by the micro-hardness test has been chosen to analyze the results (Eq. (8)). The Martens micro-hardness value used corresponds in this case to an applied maximum force of $100 \mathrm{mN}$.

$H_{M}(\mathrm{GPa})=\frac{P_{\max }}{A_{r}}=\frac{P_{\max }}{26.968 * h_{m}^{2}}$

where $\mathrm{P}_{\max }(\mathrm{mN})$ is the applied maximum load; $\mathrm{h}_{\mathrm{m}}(\mu \mathrm{m})$ is the maximum depth of penetration measured; $A_{r}=26.968 * h_{m}^{2}$ corresponds to the contact area of the indenter for the maximum depth of penetration measured.

\section{Results}

\subsection{Macroscopic study}

\subsubsection{Ceiling effect}

The experimental results are presented in the Table 6 . The relationship between the compressive strength of the mortar (Rc) and the cement matrix (Rcm) is shown in Fig. 8. From Eq. (2) and

Table 5

Contact geometry parameter of modified Berkovich indenter.

\begin{tabular}{|c|c|c|c|c|c|c|c|c|}
\hline & $\theta$ & $\omega$ & Real contact area (Ar) & Projected contact area (Ap) & $\mathrm{Ar} / \mathrm{Ap}$ & Half angle of equivalent cone & Volume & Print size \\
\hline Modified Berkovitch & $65.27^{\circ}$ & $77.03^{\circ}$ & $\sim 26.968 \mathrm{~h}^{2}$ & $\sim 24.494 \mathrm{~h}^{2}$ & 1.101 & $\sim 70.30^{\circ}$ & $\sim 8.165 \mathrm{~h}^{3}$ & $\sim 7.52 \mathrm{~h}$ \\
\hline
\end{tabular}

$\mathrm{h}(\mu \mathrm{m})$ : penetration of indenter into the material.

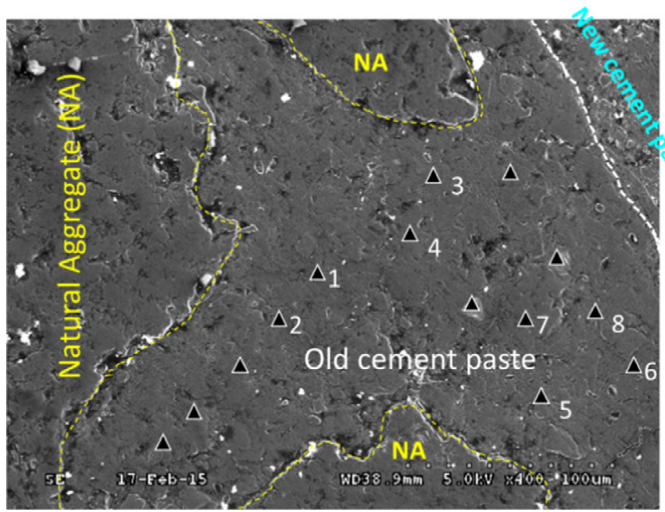

Nano-indentation test on the old cement paste

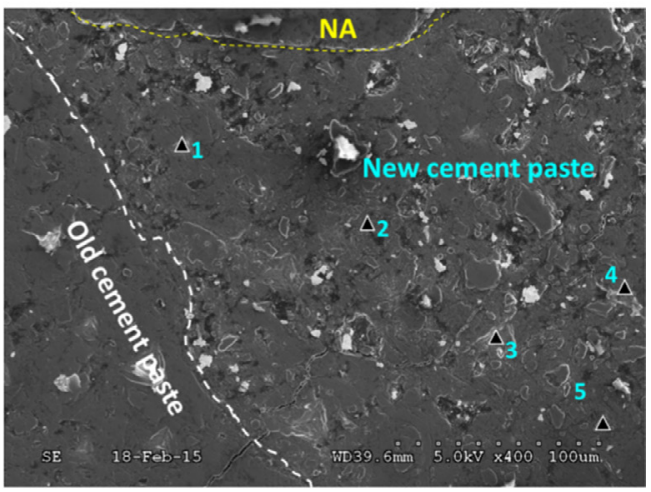

Nano-indentation test on the new cement paste

Fig. 7. Print of nano-indentation test on the old and new cement paste in the mortar based on the recycled sand 
Table 6

Experimental results for the investigation of the "ceiling effect".

\begin{tabular}{|c|c|c|c|c|c|c|c|c|}
\hline $\mathrm{W}_{\text {eff }} / \mathrm{C}$ & & 0.38 & 0.43 & 0.48 & 0.53 & 0.58 & 0.63 & 0.68 \\
\hline Slump flow & $(\mathrm{mm})$ & 338 & 348 & 346 & 288 & 299 & 349 & 324 \\
\hline $\mathrm{V}_{\text {air-entrained }} / \mathrm{V}_{\text {total }}$ & (\%) & 0 & 0 & 0 & 0 & 0 & 0 & 0 \\
\hline $\mathrm{g}$ & & 0.62 & 0.60 & 0.59 & 0.57 & 0.56 & 0.55 & 0.54 \\
\hline $\mathrm{g}^{*}$ & & 0.745 & 0.745 & 0.745 & 0.745 & 0.745 & 0.745 & 0.745 \\
\hline $\mathrm{g}^{*} / \mathrm{g}$ & & 1.20 & 1.23 & 1.26 & 1.30 & 1.33 & 1.36 & 1.39 \\
\hline$R_{c 28}^{c i}$ & (MPa) & 51.3 & 51.3 & 51.3 & 51.3 & 51.3 & 51.3 & 51.3 \\
\hline MPT & $(\mathrm{mm})$ & 0.20 & 0.23 & 0.26 & 0.29 & 0.31 & 0.34 & 0.37 \\
\hline $\mathrm{Rc}_{\mathrm{m}}{ }^{1}$ & (MPa) & 92.8 & 74.9 & 61.4 & 51.0 & 42.8 & 36.3 & 31.1 \\
\hline $\mathrm{Rc}^{2}$ & (MPa) & 53.3 & 51.2 & 47.6 & 40.2 & 36.1 & 32.1 & 28.6 \\
\hline
\end{tabular}

${ }^{1}$ Calculated by Eq. (3).

2 Obtained by compressive test on the sample $4 \times 4 \times 16 \mathrm{~cm}^{3}$.

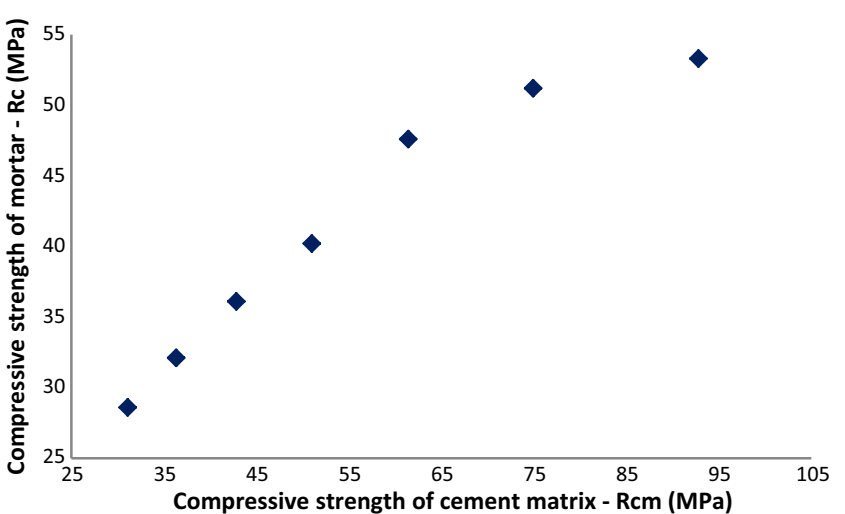

Fig. 8. Relationship between the compressive strength of the mortar and the cement matrix at 28 days.

experimental results, parameters $\mathrm{p}$ and $\mathrm{q}$ can be determined. The $\mathrm{p}$ and q parameters were obtained by regression analysis in order to minimize the relative square difference between experimental and calculated values of Rc. The calculated results are shown in Table 7. We can observe here a higher value of "p" than that obtained for NA in the literature [12], which indicates a good adhesion between the cement matrix and recycled aggregate at 28 days of hydration. This good adhesion might be due to a good chemical affinity between the two cement pastes, this point will be verified with the SEM observations. In addition, the surface roughness of the recycled aggregate due to the presence of the adherent cement paste may be one reason for this good adhesion.

However, the p/q value (99.6 MPa) is smaller than the values of natural aggregate in the study of De Larrard [12]. It exists therefore a significant "ceiling effect" for our recycled sand that will limit the strength of mortar for small values of $\mathrm{W}_{\mathrm{eff}} / \mathrm{C}$ ratio. For a very low $W_{\text {eff }} / C$ ( 0.38 for example), the strength of mortar does not exceed $60 \mathrm{MPa}$. The strength of mortar is, in this case, "controlled" by the strength of recycled aggregates. However, for an intermediate $\mathrm{W}_{\text {eff }} / \mathrm{C}$ ratio ( 0.53 for example), the strength of mortar based on the RS both depends on the strength of the cement matrix and the intrinsic strength of the aggregate.

Fig. 9 shows the compressive strength at 28 days of mortar based on the recycled sand RS_1 in two saturation states (dry

Table 7

$\mathrm{p}$ and $\mathrm{q}$ parameters in this study and in the literature.

\begin{tabular}{|c|c|c|c|c|c|}
\hline Aggregates & & $\mathrm{p}$ & $\mathrm{q}\left(\mathrm{MPa}^{-1}\right)$ & $\mathrm{p} / \mathrm{q}(\mathrm{MPa})$ & References \\
\hline Recycled sand RS_1 & & 1.298 & 0.013 & 99.6 & This study \\
\hline Crotoy & Rounded flint & 0.583 & 0 & $\infty$ & De Larrard [12] \\
\hline Boulonnais & Crushed hard limestone & 1.111 & 0.0033 & 337 & \\
\hline Arlaut & Crushed semi-hard limestone & 0.960 & 0.0040 & 241 & \\
\hline Raon & Crushed basalt & 0.651 & 0 & $\infty$ & \\
\hline Cherbourg & Crushed quartzite & 1.145 & 0.0047 & 244 & \\
\hline
\end{tabular}

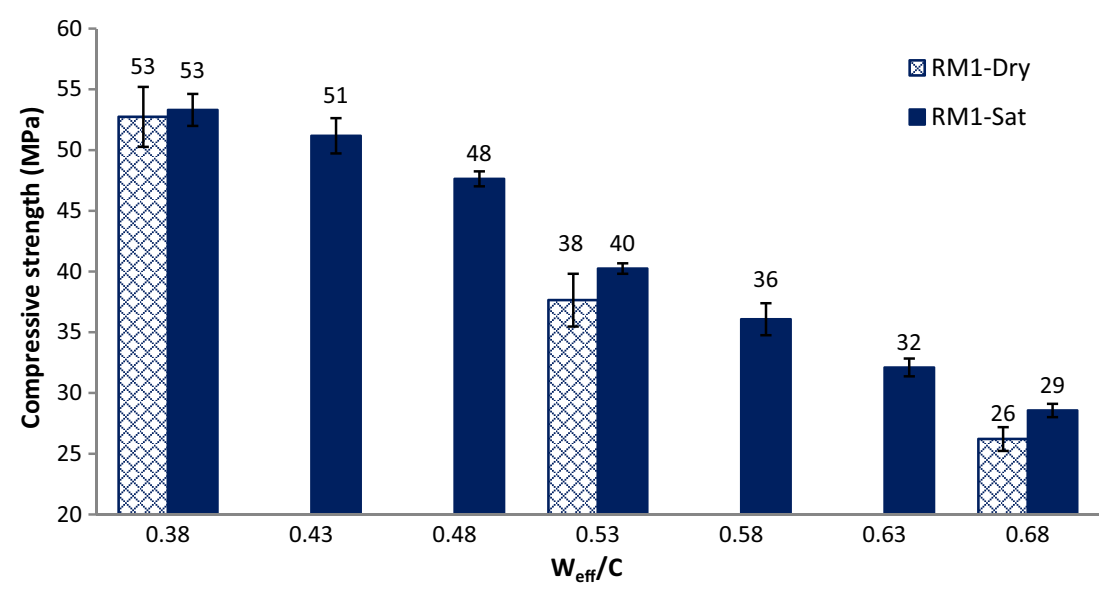

Fig. 9. Compressive strength of the mortar based on the recycled sand RS_1 at 28 days as a function of water/cement ratio. 
and saturated) as a function of $\mathrm{W}_{\text {eff }} / \mathrm{C}$ ratio. The compressive strength decreases when the $\mathrm{W}_{\text {eff }} / \mathrm{C}$ increases regardless of the initial saturation state of recycled sand.

With a low $\mathrm{W}_{\text {eff }} / \mathrm{C}(0.38)$, the strength of cement matrix is high and the strength of the two mortars is controlled by the strength of aggregates ("ceiling effect"). On the contrary, for a high $\mathrm{W}_{\text {eff }} / \mathrm{C}$ (0.68), the strength of the matrix is lower compared to that of aggregates and it determines the strength of mortars. We can also notice a small difference of compressive strength between the mortar containing dry and saturated recycled sand that is more significant when the $W_{\text {eff }} / C$ increases ( 1 and 9\% respectively for $\mathrm{W}_{\text {eff }} / \mathrm{C}=0.38$ and 0.68 ). This small difference may be assigned to the difficulty to determine the amount of effective water in the case of porous aggregate due to the lack of efficient method for the measurement $[19,32,33]$.

\subsubsection{Mechanical properties}

The compressive strengths obtained after 2 and 28 days of curing are presented in Fig. 10. As can be seen, the mortars based on natural sand (NS) present larger compressive strengths than the mortars based on recycled sand (RS_2). The strength loss is almost $20 \mathrm{MPa}$ at 28 days when replacing NS by RS_2. This loss of strength can be explained by a lower strength of RS compared to the strength of NS and/or a lower quality of the cement paste that could be due to an incorrect estimation of water absorption coefficient.

We can also notice for both sands that the initial saturation state of aggregates has little influence on the mechanical properties if we work with the same $\mathrm{W}_{\text {eff }} / \mathrm{C}$ ratio. This result was expected in the case of natural sand with a low porosity, and is in agreement with previous studies on sands of limestone with low porosity [13]. However, this result is more surprising in the case of RS_2. Indeed, it had previously been shown in the case of porous limestone aggregates that the effective water calculation underestimates the water released by the aggregates. This excess water carries with it a more porous transition zone and leads to a decrease in the mechanical properties of mortar based on saturated aggregates in comparison to mortar containing dried aggregates [13]. In order to better understand this result, SEM study has been performed in order to investigate the ITZ in the recycled aggregate concrete.

We can also observe that the mortar's compressive strength obtained with recycled sand RS_2 (Fig. 10) is much lower than that made with RS_1 with the same $\mathrm{W}_{\text {eff }} / \mathrm{C}$ (Fig. 9). It is difficult to compare these two systems because the compositions of two mortars are different (differences in sands PSDs, differences in sands volumes ...). These differences in compositions lead to significant

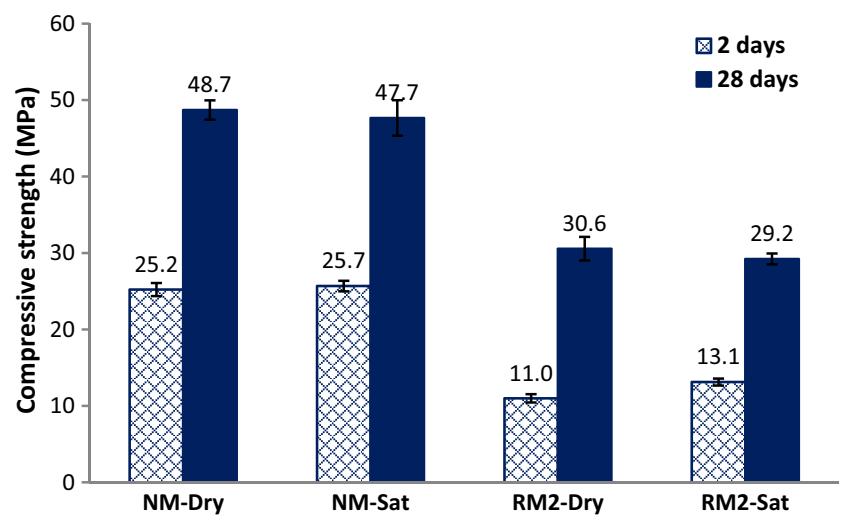

Fig. 10. Compressive strength of mortars after 2 and 28 days of hydration (NM-dry: mortar based on dry natural sand; NM-Sat: mortar based on over-saturated natural sand) differences in the workability of the two mortars. Mortar made with RS_1 was a self-compacting mortar, on the contrary, the workability of mortar made with RS_2 was much lower, and a significant quantity of air could have been entrained during placing. Moreover, the maximum paste thicknesses in the two mortars are significantly different $(0.294$ for RM1 and 0.118 RM2) which could induce a decrease in strength of about $10 \%$ according to Eq. (3).

\subsection{Microscopic study}

\subsubsection{SEM observation and image analysis}

SEM images of mortars with dry and oversaturated sand at 2 and 28 days are presented in Figs. 11-14. In the case of mortar based on natural sand, the border between natural aggregate and cement paste can easily be found; it is a natural siliceous aggregate so the difference is very clear.

In the case of RM2, at two days of hydration, the degree of hydration of the new cement paste is still low, but the old cement paste is mature, so the boundary between the two pastes can easily be distinguished. With RM2-Sat at two days of hydration, a duplex film of large width is formed at the surface of the former paste. This duplex film zone is rich in Portlandite and has been described by previous authors $[3,13,34]$.

At 28 days, in the case of RM2-Dry, we cannot distinguish anymore the boundary between the old and new cement paste indicating a good continuity between the two cement pastes. On the contrary, for RM2-Sat, the layer of Portlandite is still present which permits to plot the boundary between the old and new cement paste, this layer leads to the filing of the ITZ with hydration products. In both cases (dry or saturated aggregate) a good adhesion between old and new cement paste can be expected. This observation confirms the obtained result in the "ceiling effect" investigation which showed a high " $p$ " value.

Fig. 15 presents the variation of average porosity over a distance of $80 \mu \mathrm{m}$ from the aggregate after 2 and 28 days of hydration. We can observe for mortars made with the natural sand (NM) a high porosity at the interface that reduces at a distance around $30 \mu \mathrm{m}$. These results are very similar to those reported in the literature $[13,22,31,23]$ and are explained by the so-called "wall effect" [35]: the packing of large anhydrous cement grains closed to the aggregate is looser and leads to a zone of higher porosity. As the hydration proceeds between 2 and 28 days, we can observe a decrease in porosity.

At 2 days of hydration, in the case of RM2, a significant decrease in porosity in the first ten microns compared to the ITZ of NM is observed for saturated aggregate. This decrease of porosity in the first $10 \mu \mathrm{m}$ is explained by the presence of the duplex film at the aggregate surface which is important in the case of saturated aggregate. The reduction of porosity at a distance around $30 \mu \mathrm{m}$ at two days is not so straight forward as for NM but we can still observe this profile if we follow the variation of anhydrous phases with distance (wall effect) (Fig. 16). However, the wall effect is more important for the recycled sand at over-saturated state. This result may be due to the draining of water out of recycled aggregate that can push the cement grains away from the surface of the aggregates. The higher porosity of RM2-Sat seems also to favor the hydrate transport in the ITZ and the duplex film formation especially when these aggregates are in a wet state as previously reported in a previous study with high porosity natural aggregate [13].

The difference of porosity between the mortar based on the dry and oversaturated sand has also been observed in the study of Nguyen [13] on porous limestone aggregates. But the difference in the case of RM2 (Dry and Saturated) is lower than the in this previous study. 

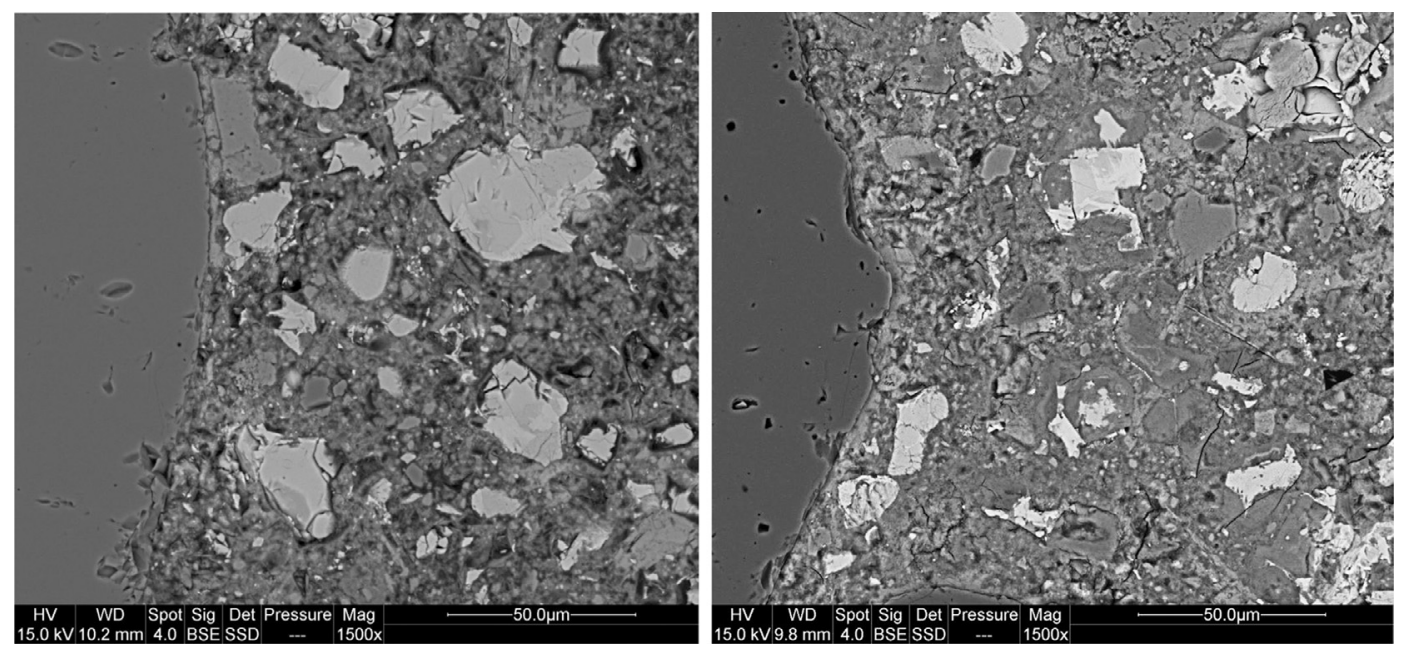

Fig. 11. BSE images of mortar based on dry natural sand (left: 2 days; right: 28 days).
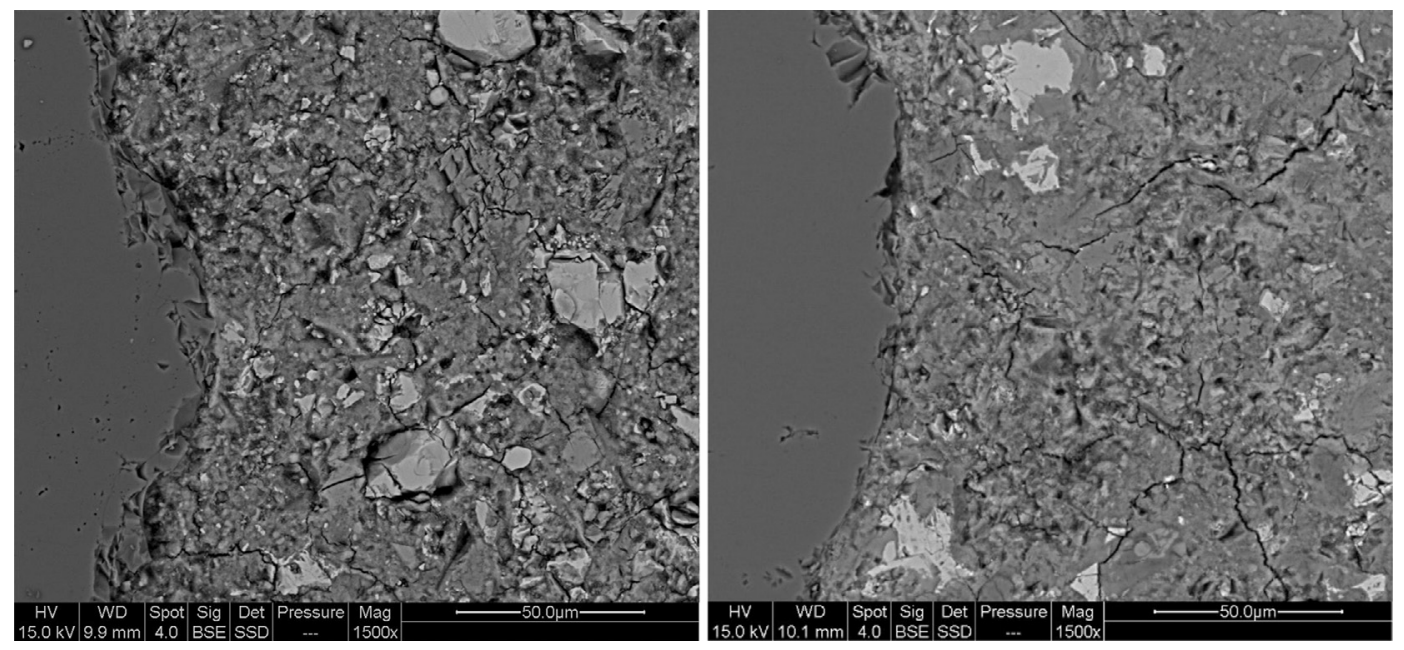

Fig. 12. BSE images of mortar based on over-saturated natural sand (left: 2 days; right: 28 days).
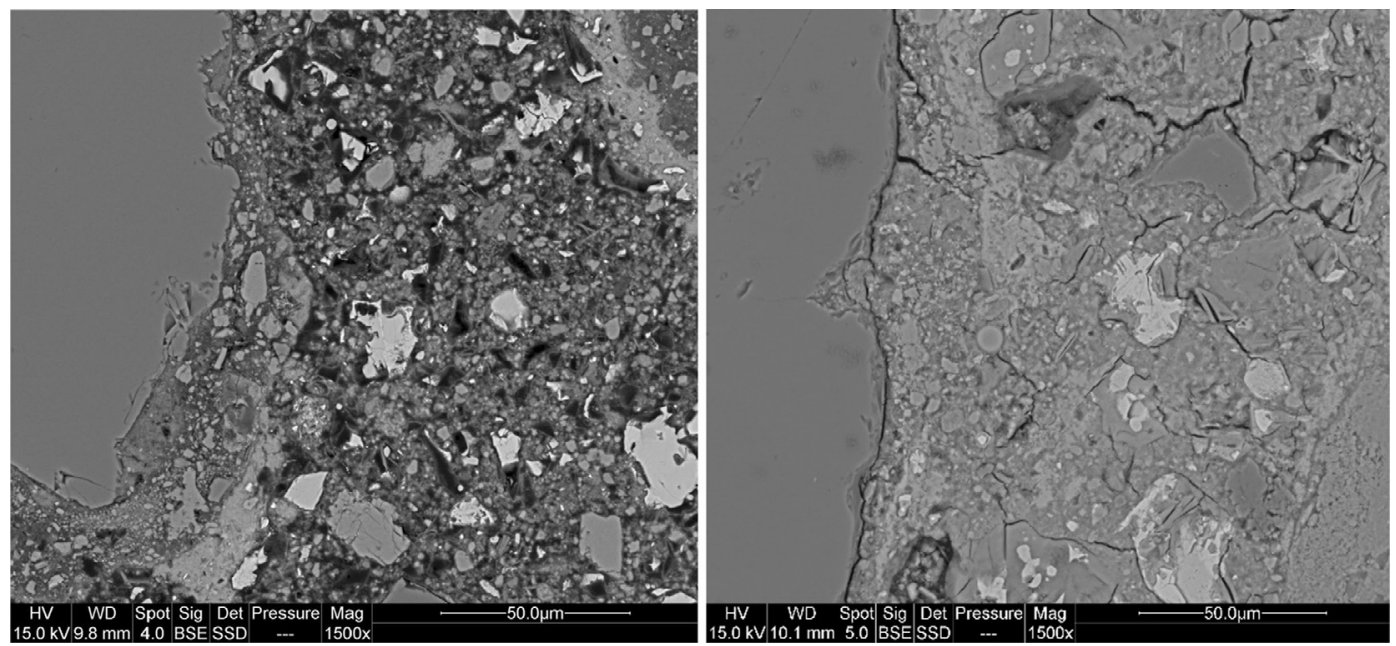

Fig. 13. BSE images of mortar based on dry recycled sand RS_2 (left: 2 days; right: 28 days). 

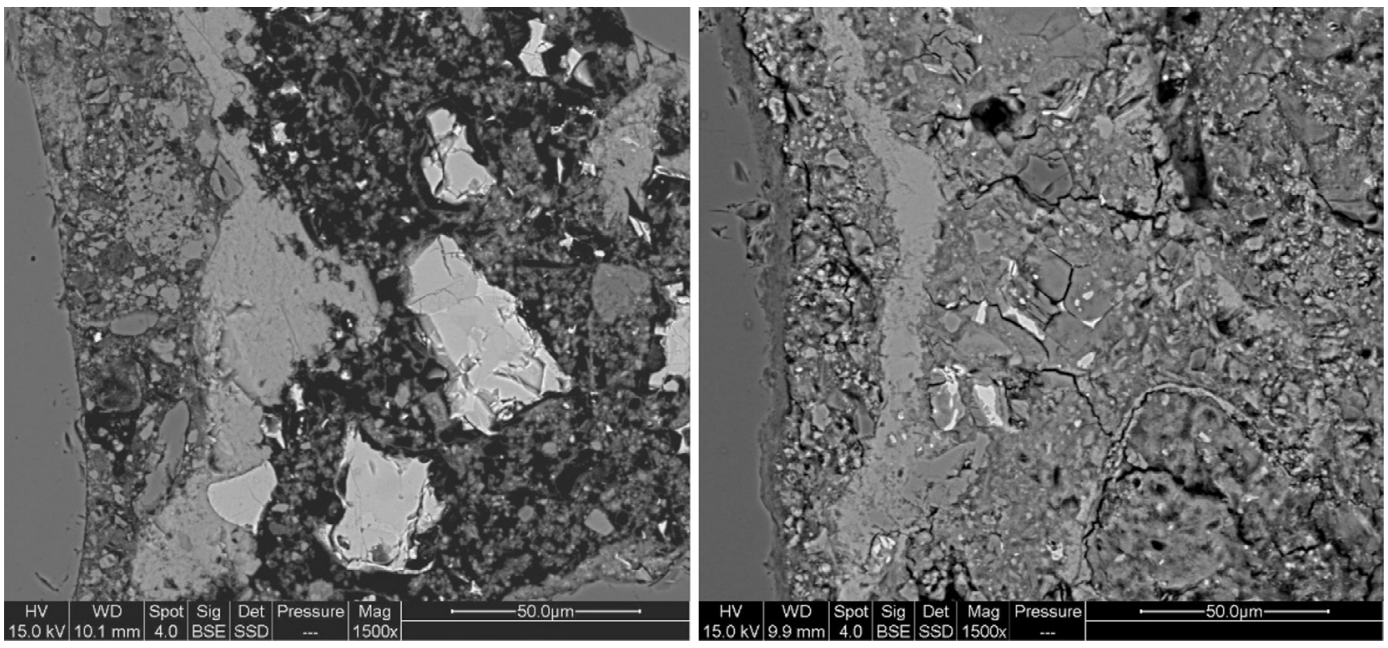

Fig. 14. BSE images of mortar based on over-saturated recycled sand RS_2 (left: 2 days; right: 28 days).

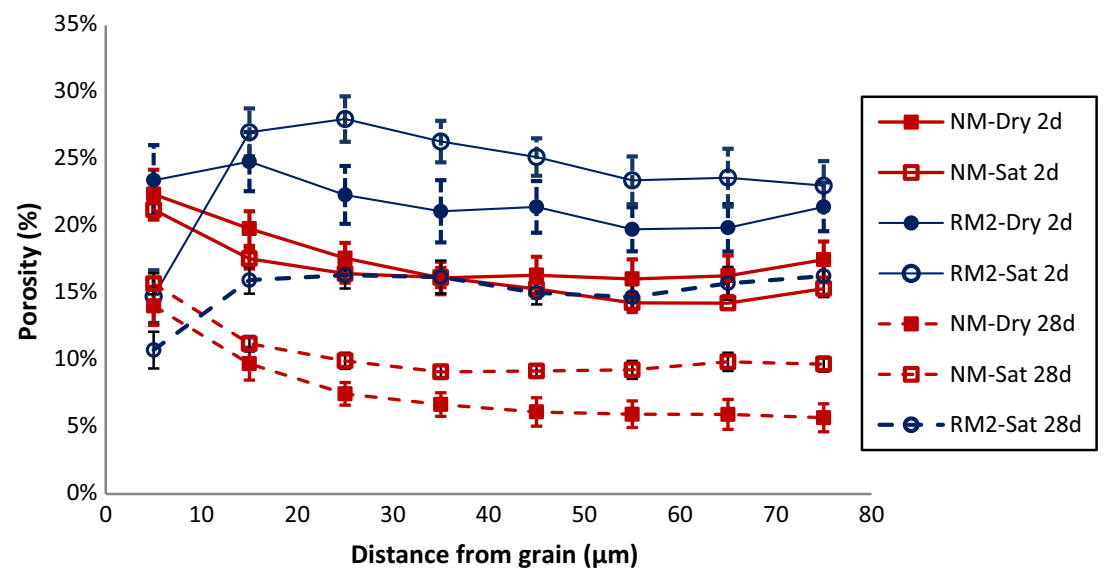

Fig. 15. Average porosity of ITZ at 2 and 28 days with distance from the aggregate (errors bars correspond to \pm confidence interval $1.96^{*} \sigma / \sqrt{n}$ ( $\sigma$ : standard deviation, $\mathrm{n}$ : number of analytical image [36]).

At 28 days, in the case of RM-Sat mortars, we still observe the presence of Portlandite at the aggregate surface and then the porosity is more or less constant with the distance from aggregate. The porosity is still higher compared to NM mortars.

As can be seen in the Figs. 15 and 16, the variation of porosity and anhydrous phases is significant in the first $60 \mu \mathrm{m}$. After that,

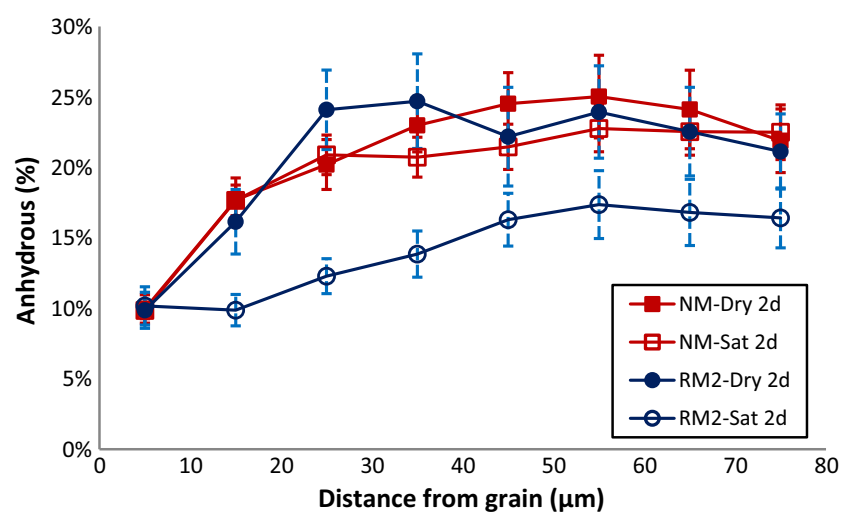

Fig. 16. Gradient of anhydrous cement in ITZ at 2 days (errors bars correspond to confidence interval $\pm 1.96^{*} \sigma / \sqrt{n}$ ( $\sigma$ : standard deviation, $\mathrm{n}$ : number of analytical image [36]) these parameters remain approximately constant. We can therefore consider that the maximal width of ITZ is about $60 \mu \mathrm{m}$ in our mortars.

Table 8 presents the average porosity of ITZ from 0 to $60 \mu \mathrm{m}$ and the average porosity of ITZ from 10 to $60 \mu \mathrm{m}$ from the aggregate surface. The porosity between 10 and $60 \mu \mathrm{m}$ does not take into account the layer of Portlandite that is present at the surface of the old cement paste (duplex film). Comparing both ITZ of mortars made from recycled sand, the average porosity of the ITZ $(0-60 \mu \mathrm{m})$ in both saturation states is close $(22.2 \%$ and $24.1 \%$ respectively for RM-Dry and RM-Sat). However the saturation state, in the case of $\mathrm{RM} 2$, significantly influences the distribution of the porosity in this zone. It can be seen that the porosity between 10 and $60 \mu \mathrm{m}$ is much larger when recycled aggregates are saturated. This result could be due first to a release of water from the saturated RCA towards the ITZ and then to the transport of hydrates, from the bulk matrix to the ITZ.

\subsubsection{Nano-indentation test}

Fig. 17 presents the results of nano-indentation tests under the SEM for mortars based on recycled sand (dry and over-saturated) at 28 days of hydration. Three different phases have been characterized: natural aggregate, old and new cement paste. However, the study of variation of micro-hardness form distance to aggregate was not possible because of the high heterogeneity of the ITZ. 
Table 8

Average porosity of ITZ.

\begin{tabular}{|c|c|c|c|c|c|c|c|}
\hline Nomination & NM-Dry $2 \mathrm{~d}$ & NM-Dry $28 \mathrm{~d}$ & NM-Sat $2 \mathrm{~d}$ & NM-Sat $28 \mathrm{~d}$ & RM2-Dry 2 d & RM2-Sat 2 d & RM2-Sat $28 \mathrm{~d}$ \\
\hline Average porosity of the ITZ at $(0-60 \mu \mathrm{m})(\%)$ & 18.1 & 8.3 & 16.8 & 10.7 & 22.2 & 24.1 & 14.8 \\
\hline Average porosity of the ITZ at $(10-60 \mu \mathrm{m})^{\mathrm{a}}(\%)$ & 17.2 & 7.2 & 16.0 & 9.7 & 21.9 & 26.0 & 15.7 \\
\hline
\end{tabular}

a $10-60 \mu \mathrm{m}$ bands zone from the aggregate, the first $10 \mu \mathrm{m}$ of duplex films are not taken in account in the calculation of the average porosity.

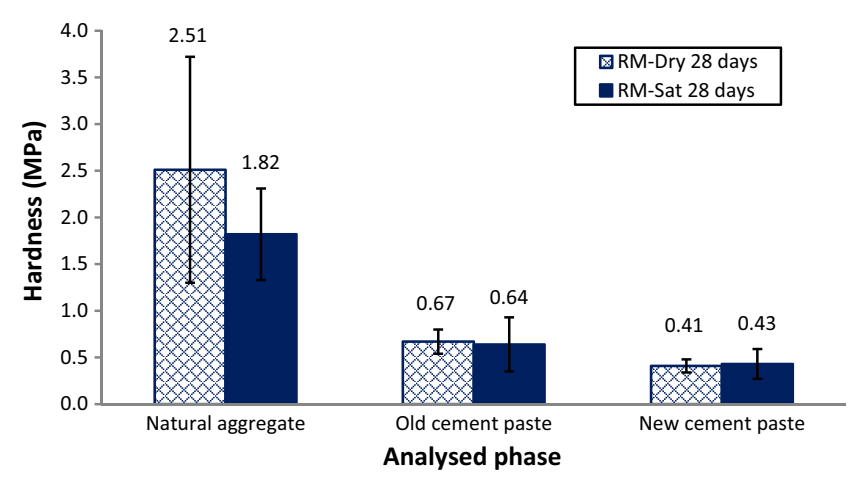

Fig. 17. Micro-hardness of different phases of mortar based on the recycled sand.

We can observe that the micro-hardness value of the natural aggregates is highest. In all cases, the micro-hardness of old cement paste is higher than that of new cement paste. It could be observed that the initial saturation state does not influence the micro-hardness of the new cement matrix. Indeed, the microhardness of two new cement matrixes is identical for two mortars based on the dried and over-saturated recycled sand. However, the difference of micro-hardness is more important between the cement pastes (old and new) and natural aggregate. The maximum concentration of stress and deformation may therefore be preferably present in the cement paste.

For mortars based on recycled sand, the image analysis results confirm that the average porosity of the two ITZ is very similar regardless of the initial state of saturation of the aggregates. The indentation test results also confirm that the micro-hardness of two new cement pastes are very close. At the microscopic level, we do not observe significant differences between the mortar containing dry and saturated recycled sand in terms of ITZ porosity and hardness of new cement pastes. These observations are in agreement with low differences of compressive strengths between mortars containing dry and oversaturated recycled sand.

\section{Conclusions}

At the macroscopic scale, by the investigation on the "ceiling effect", we obtained a high value of parameter "p" that means a good adhesion between the RCA and the new cement matrix at 28 days of hydration. This result might be attributed to a good chemical affinity between the two cement pastes, and to the surface roughness of the recycled aggregate. A lower value of $\mathrm{p} / \mathrm{q}$ ratio for RS compared to natural aggregates reflects a significant "ceiling effect" of our recycled sand. This effect limits the strength of mortars at low $\mathrm{W}_{\text {eff }} / \mathrm{C}$.

This "ceiling effect" may explain the low influence of moisture condition of used aggregates on the mechanical properties of mor$\operatorname{tar}$ at $\mathrm{W}_{\text {eff }} / \mathrm{C} \leq 0.5$. Therefore the saturation state of aggregate has little effect on the strength of mortar. However, for a high $\mathrm{W}_{\mathrm{eff}} / \mathrm{C}$ value, the strength of the matrix is lower compared to that of aggregates and it determines the strength of mortars. We can observe in that case a little influence of saturation state on the strength of mortar.
The microstructure of mortar based on recycled sand is characterized by the image analysis of ITZ and nano-indentation tests under the SEM. The ITZ of RM at two days of hydration has been easily found with a visible difference between the new and old cement paste. However, in the case of RM-Dry at 28 days of curing, the new ITZ has not been found because of a good continuity between the old and new cement paste. The new ITZ of RM-Sat at 28 days has been found with a layer of Portlandite at the surface of old cement paste. In both cases (dry or sat), this result confirms the good adhesion obtained in the "ceiling effect" investigation (high "p" value obtained).

With the RM, the moisture conditions of aggregate influence significantly the porosity distribution in ITZ. A decrease of porosity in the first ten micrometers is observed for saturated aggregates due to the precipitation of Portlandite. But the average porosity of ITZ of two mortars at two days of hydration, RM-Dry or RMSat, is identical.

Following the nano-indentation test under the SEM at 28 days of hydration, the moisture conditions of recycled sand do not influence the micro-hardness of the new cement matrix. The microhardness value of new cement matrix is lower than that of old cement matrix. This result is not generalizable for all recycled aggregates, it depends also on the relative strength between the new and old cement paste. The high difference of hardness, in our case, is found between the cement paste and natural aggregate. Therefore the maximum concentration of stress and deformation may be shown in the cement paste.

As can be seen, the porosity of new ITZ and the micro-hardness of new cement paste in two moisture conditions of recycled aggregates are identical. The results of image analysis and nanoindentation tests are also in agreement with the low difference of compressive strength between two mortars based on dried and over-saturated aggregates at the macroscopic scale.

From an industrial point of view, our results suggest that the initial saturation state has a little influence on the water absorption of RCA. However, this conclusion would have to be generalized to other RCA.

\section{Acknowledgments}

The authors thank the National Project RECYBETON and ANR ECOREB which supported this research.

The authors would like to acknowledge J.-M. Taulemesse for his support during the SEM experiments, A. Diaz, C. Buisson for their experimental support in the laboratory (EMA) and also G. Louis for his support during the nano-indentation test experiments and $\mathrm{V}$. Thierry for the nano-indentation test samples preparation (EMD).

\section{References}

[1] G.A. Blengini et al., Life Cycle Assessment guidelines for the sustainable production and recycling of aggregates: the Sustainable Aggregates Resource Management project (SARMa), J. Clean. Prod. 27 (2012) 177-181.

[2] K.L. Scrivener, P.L. Pratt, Characterisation of interfacial microstructure, in: J.C. Maso (Ed.), Interfacial Transition Zone in Concrete, vol. 2, E F \& N SPON, 1996, pp. 3-18 (no. 1).

[3] J.P. Ollivier, J.C. Maso, B. Bourdette, Interfacial transition zone in concrete, Adv. Cem. Based Mater. 2 (1) (1995) 30-38. 
[4] D.P. Bentz, E.J. Garboczi, Computer Modelling of Interfacial Transition Zone: Microstructure and Properties, in: Engineering and Transport Properties of the Interfacial Transition Zone in Cementitious Composites, 1999, pp. 349-385.

[5] K.L. Scrivener, A.K. Crumbie, P. Laugesen, The interfacial transition zone (ITZ) between cement paste and aggregate, Interface Sci. 12 (2004) 411-421.

[6] T. Du, W.H. Wang, H.L. Lin, Z.X. Liu, J. Liu, Experimental study on interfacial strength of the high performance recycled aggregate concrete, Earth Sp. 2010 (2010) 2821-2828.

[7] J. Xiao, W. Li, Y. Fan, X. Huang, An overview of study on recycled aggregate concrete in China (1996-2011), Constr. Build. Mater. 31 (2012) 364-383.

[8] A. Rasheeduzzafar, A. Khan, Recycled concrete a source for new aggregate, Cem. Concr. Aggregates 6 (1984) 17-27.

[9] V.W.Y. Tam, X.F. Gao, C.M. Tam, Microstructural analysis of recycled aggregate concrete produced from two-stage mixing approach, Cem. Concr. Res. 35 (6) (2005) 1195-1203.

[10] M. Etxeberria, E. Vazquez, A. Mari, Microstructure analysis of hardened recycled aggregate concrete, Mag. Concr. Res. 58 (10) (2006) 683-690.

[11] G.C. Lee, H.B. Choi, Study on interfacial transition zone properties of recycled aggregate by micro-hardness test, Constr. Build. Mater. 40 (2013) 455-460.

[12] F. De Larrard, A. Belloc, The influence of aggregate on the compressive strength of normal- and high-strength concrete, ACI Mater. J. 94 (1997) 5.

[13] T.-D. Nguyen, G. Le Saout, P. Devillers, E. Garcia-Diaz, The effect of limestone aggregate porosity and saturation degree on the interfacial zone, in: The 2nd International Symposium on Cement-based Materials for Nuclear Wastes, 2014, p. 13.

[14] Z. Zhao, S. Remond, D. Damidot, W. Xu, Influence of fine recycled concrete aggregates on the properties of mortars, Constr. Build. Mater. 81 (2015) 179186.

[15] D.-T. Dao, (Multi-)Recyclage Du Béton Hydraulique, Ifsttar Nantes, Nantes, 2012.

[16] Recybéton, Projet National Recybéton, http://www.pnrecybeton.fr/, 2012.

[17] EN 196-1, Methods of Testing Cement - Part 1: Determination of Strength, European Committee for Standardization, 2006.

[18] Z. Zhao, S. Remond, D. Damidot, W. Xu, Influence of hardened cement paste content on the water absorption of fine recycled concrete aggregates, J. Sustain. Cem. Mater. 2 (3-4) (2013) 186-203.

[19] T. Le, S. Rémond, G. Le Saout, E. Garcia-Diaz, Fresh behavior of mortar based on recycled sand - influence of moisture condition, Constr. Build. Mater. 106 (2016) 35-42.

[20] NF EN 413-2, Masonry Cement, European Committee for Standardization, 2006.
[21] J. Zhang, G.W. Scherer, Comparison of methods for arresting hydration of cement, Cem. Concr. Res. 41 (10) (2011) 1024-1036.

[22] K.L. Scrivener, E.M. Gartner, Microstructural Gradients in Cement Paste around Aggregate Particles, MRS Proc. 114 (1987) 77-86.

[23] S. Diamond, Considerations in image analysis as applied to investigations of the ITZ in concrete, Cem. Concr. Compos. 23 (2-3) (2001) 171-178.

[24] L. Basheer, P.A.M. Basheer, A.E. Long, Influence of coarse aggregate on the permeation, durability and the microstructure characteristics of ordinary Portland cement concrete, Constr. Build. Mater. 19 (9) (2005) 682-690.

[25] A. Elsharief, M.D. Cohen, J. Olek, Influence of aggregate size, water cement ratio and age on the microstructure of the interfacial transition zone, Cem. Concr. Res. 33 (11) (2003) 1837-1849.

[26] S. Hemavibool, The Microstructure of Synthetic Aggregate Produced from Waste Materials and its Influence on the Properties of Concrete, University of Leeds, 2007.

[27] A.R. Brough, A. Atkinson, Automated identification of the aggregate-paste interfacial transition zone in mortars of silica sand with Portland or alkaliactivated slag cement paste, Cem. Concr. Res. 30 (6) (2000) 849-854.

28] H.S. Wong, M.K. Head, N.R. Buenfeld, Pore segmentation of cement-based materials from backscattered electron images, Cem. Concr. Res. 36 (6) (2006) 1083-1090.

[29] A. Delesse (Procédé mécanique pour déterminer la composition des roches), Ann. Mines 13 (1848) 379-388.

[30] H. Chen, W. Sun, P. Stroeven, L.J. Sluys, Overestimation of the interface thickness around convex-shaped grain by sectional analysis, Acta Mater. 55 (11) (2007) 3943-3949.

[31] M.K. Head, H.S. Wong, N.R. Buenfeld, Characterising aggregate surface geometry in thin-sections of mortar and concrete, Cem. Concr. Res. 38 (10) (2008) 1227-1231.

[32] A. Djerbi Tegguer, Determining the water absorption of recycled aggregates utilizing hydrostatic weighing approach, Constr. Build. Mater. 27 (1) (2012) $112-116$.

33] A.Z. Bendimerad, E. Roziere, A. Loukili, Combined experimental methods to assess absorption rate of natural and recycled aggregates, Mater. Struct. (2014).

[34] B.D. Barnes, S. Diamond, W.L. Dolch, The contact zone between Portland cement paste and glass 'aggregate' surfaces, Cem. Concr. Res. 8 (1978) 233244

[35] K.L. Scrivener, Backscattered electron imaging of cementitious microstructures: understanding and quantification, Cem. Concr. Compos. 26 (8) (2004) 935-945.

[36] G. Saporta (Probabilités, analyse de données et statistique), TECHNIP, 1990. 